\title{
2-D Numerical modelling of hydrodynamic and sediment transport in Agathis Lake
}

\author{
Rian Mantasa Salve Prastica ${ }^{1, *}$, Herr Soeryantono ${ }^{1}$, and Dwinanti Rika Marthanty ${ }^{1}$ \\ ${ }^{1}$ Civil Engineering Department, Faculty of Engineering, Universitas Indonesia, Depok, Indonesia
}

\begin{abstract}
Problems about lakes are inclining every year, especially for water quality problem. Policy decisions to conserve lakes could be well achieved by data prediction. Modelling by using software could describe the future conditions of lake and give policymakers to legislate the best alternative solution. This research studies Agathis lake characteristics. The lake is situated in Universitas Indonesia, Depok, West Java, Indonesia. The research employs Resource Modelling Associates (RMA) program to simulate hydraulic and water quality data. This research will determine the most representative water sampling location and type of TSS for calibration analysis. Next, this research simulates two scenarios of lake's conditions. The simulation is run by modelling the lake with wetland scenario and with rainy season scenario. After running several iterations, the most representative water sampling location is in the upper part of the water column and the best model of TSS is mixed TSS. Two simulated scenarios produce a reasonable result and could predict the future conditions of Agathis Lake. The research recommends that the sediment trap, that is located in the inlet of the lake, should be well-treated regularly in rainy season, and Universitas Indonesia should manage and arrange the suitable plants to be applied in the future constructed wetland.
\end{abstract}

\section{Introduction}

The prediction data of water quality due to soil erosion and sediment is highly needed to do conservation towards water bodies like rivers and lakes [1]. Modelling gives prediction data that provides information on water quality in the present and future days. In this condition, the developer or manager could make policy about conservation with the model output data. Types of the models have been discussed by Parsons et al. [2] and the models could be used widely. Furthermore, years by years, the technology of modelling concept is developed. Young et al. [3] made a conceptual model named Water quality AGNPS in a small catchment. Jakeman et al. [4, $5,6]$ and Dietrich et al. [7] made an empirical and conceptual model called IHACRES-WQ in the catchment scale. The output of the program is a runoff, sediment, and nutrients. Kusumah [8], Izzaty [9]. And Hermawan [10] employed Resource Modelling Associates (RMA) to simulate water quality data prediction.

The present research provides further research result from initial findings [11, 12, 13]. Resource Modelling Associates (RMA) is employed to model hydraulic and water quality data in the study area, Agathis Lake. This advanced research is developed from previous research [11]. The calibration analysis is conducted to make the Resource Modelling Associates (RMA) program result could represent the actual field data of Agathis Lake. The research observes total suspended solids (TSS) as the main pollutant in Agathis Lake. The previous research [11] suggests to analyze the most representative water sampling location in Agathis Lake with the least sum of squared error (SSE) percentage. The current analysis is according to the physical existing condition. This research aims to define the representative sampling locations in Agathis Lake and develops two scenarios simulations to observe and to predict the future conditions of Agathis Lake.

\section{Research method}

Previous research about grand methodology [12] discusses that the RMA program uses the finite element method. Calibration analysis would be done by conducting field data sampling and total suspended solid (TSS) laboratory tests. The most representative sample locations of Agathis Lake would be defined by analyzing the least SSE of calibration stage. The least SSE will be the final coefficient to run the model in various conditions. Two scenarios of lake's condition would be modelled and analyzed. The first simulation is developing lake with constructed wetland. This method is done by redeveloping the RMA program and adding more meshes in the program. The program will run and then the program output will be analyzed. The second simulation

\footnotetext{
* Corresponding author: rianmantasasp@gmail.com
} 
will use the existing physical condition of Agathis Lake by changing the inflow discharge that enters to the water body. The second simulation is run due to high intensity of rainfall condition. These simulations are run to predict the condition of Agathis Lake and to decide better policy recommendation in order to achieve the lake management goal [3]

\section{Results and discussion}

\subsection{Study area}

Agathis Lake is represented by symbol $A$ in Figure 1. This lake is the upper part of the cascade-pond system in Universitas Indonesia. Besides that, this lake is directly connected to drainage system of settlements. These conditions are the reason to take the lake as the model.

\subsection{Representative samples}

The field data sampling is conducted in three different locations of water column of the lake. The first location is $0-30 \mathrm{~cm}$ under the water surface (surface profile), the second location is $45-65 \mathrm{~cm}$ under surface water (column profile), and the third location is $45-65 \mathrm{~cm}$ from the surface water (bed profile). Water samples are taken from all three locations. Then, TSS is analysed and then is compared with the model prediction. Table 1 shows the analysis of the three locations samples and model prediction. A problem arises when this analysis is conducted. The model should define the characteristics of TSS model. There are three assumptions of type of TSS in this program, so the laboratory tests analyse all of the three types of TSS. They are TSS itself (mixed of volatile and fixed solids), volatile solid, and fixed solid contents should be completed to make sure the type of TSS that modelled in the RMA program. Table 2 shows the result of the type of TSS in the Agathis Lake that is modelled in the research.

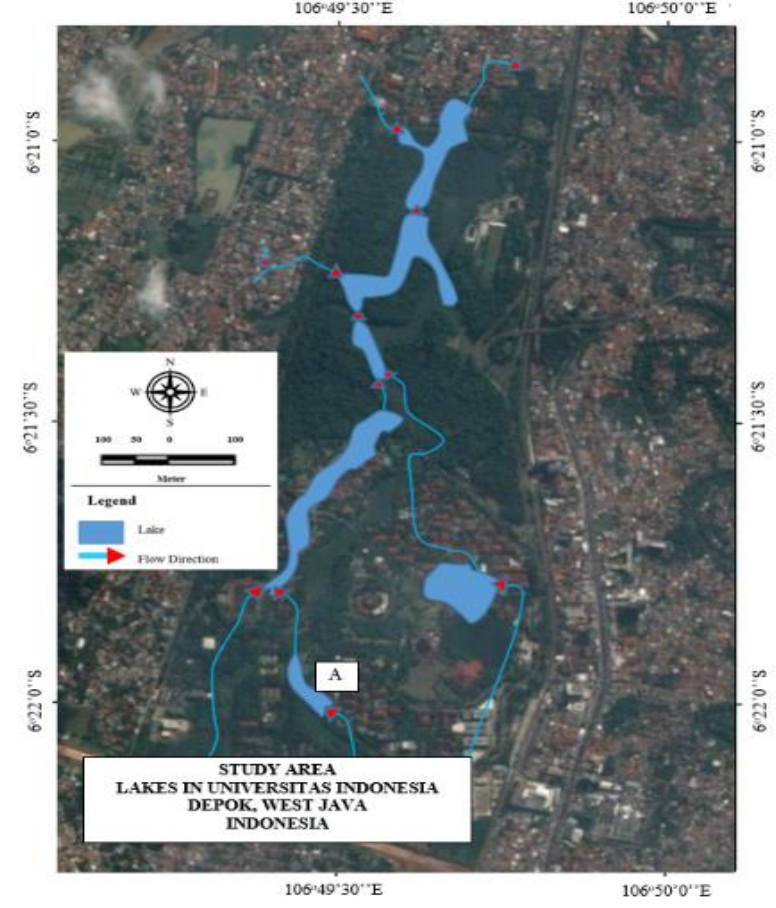

Fig. 1. Lakes in Universitas Indonesia [2]

According to the Table 1 and Table 2, the representative sample in this model is located in the surface profile and the type of TSS is TSS (mixed).

\subsection{Simulation I: Agathis Lake with Wetland}

The difference of constructing RMA-GEN at this stage is the presence of wetland into the system. After making the discretization of Agathis Lake using RMA-GEN, the next step is inputting the basic elevation in each node. Elevations that can be read by RMA-10 and RMA-11 are relative elevations, which assume the water level elevation in the initial condition is $0.00 \mathrm{~m}$. The basic elevation for Agathis Lake is made in the minus form, signifying its position beneath the surface of the water. This study used contour and bathymetry maps in the form of secondary data that has been processed in 2017 by Universitas Indonesia. Below figures are the result of discretization of Agathis Lake with its scenario condition through a wetland. Figure 2 depicts the discretization of Agathis Lake with wetland. Figure 3 shows the ordering process according to the discretization. Then, Figure 4 depicts the nodal with depth elevation input. 


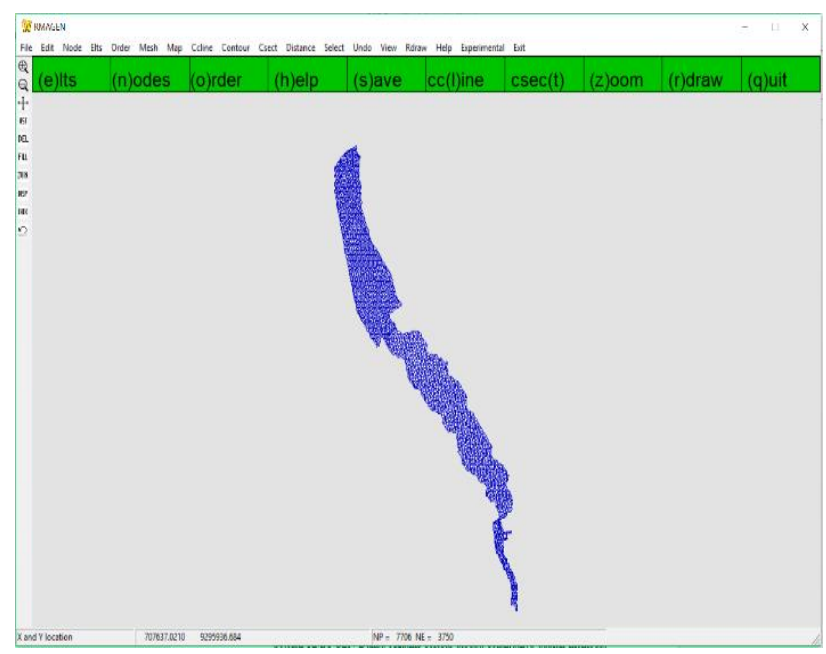

Fig. 2. Discretization of Agathis Lake with Wetland

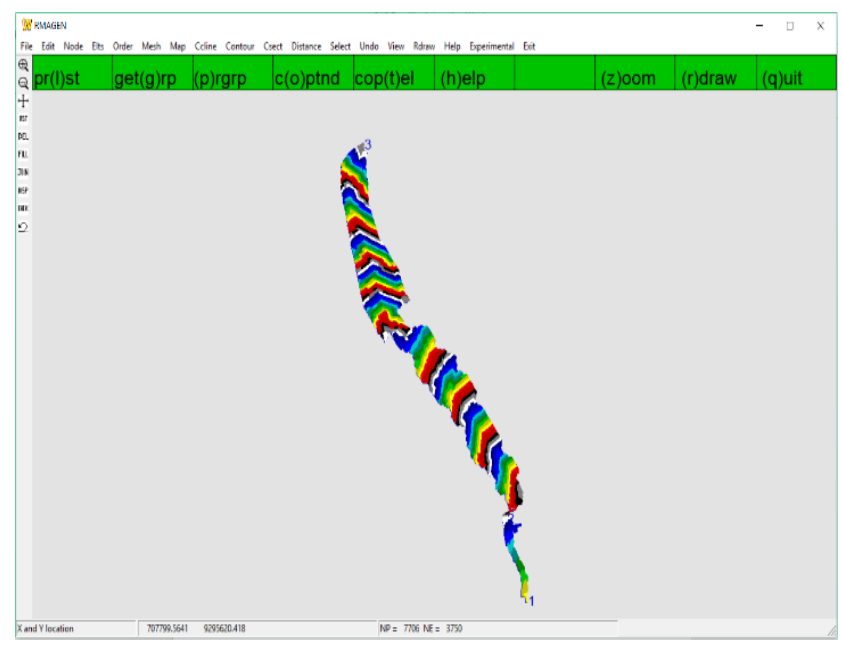

Fig. 3. Ordering Process of Discretization

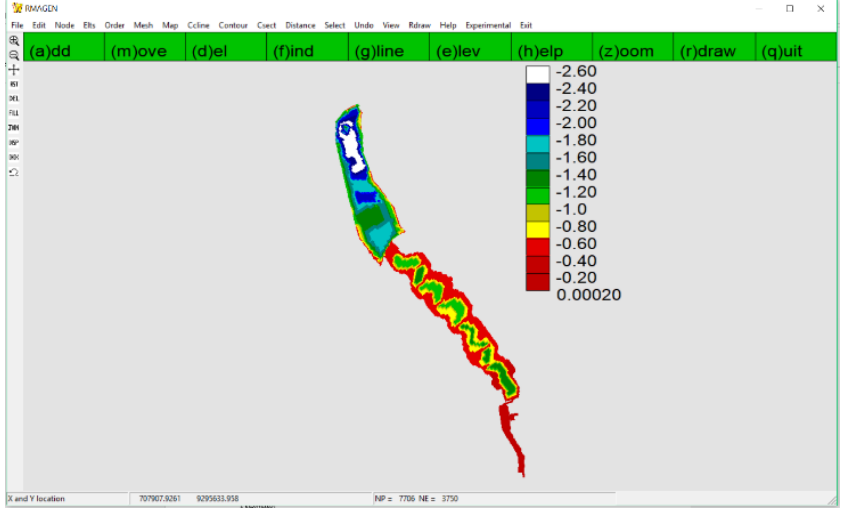

Fig. 4. Nodal with depth elevation input

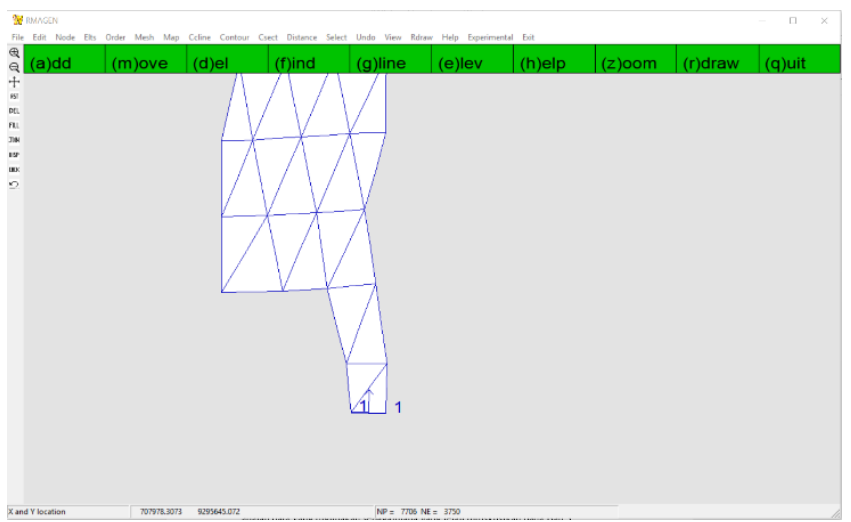

Fig. 5. Inflow location

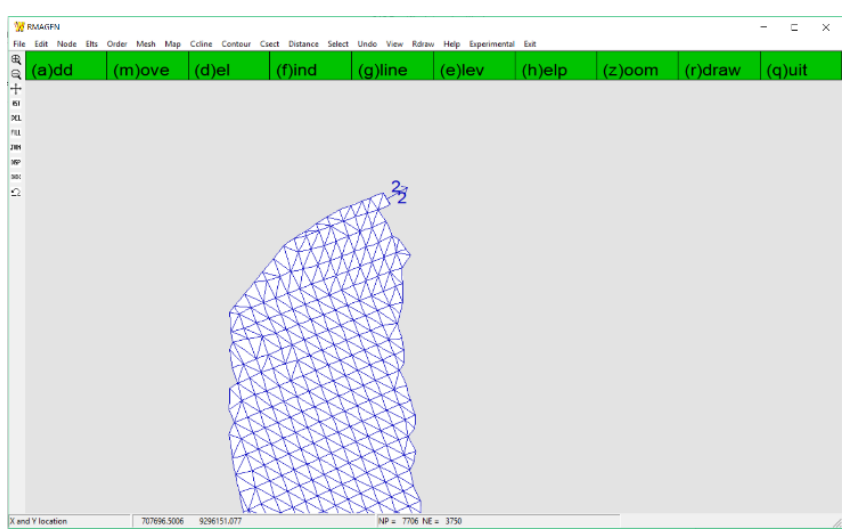

Fig. 6. Outflow location

Table 1. TSS Results in various sampling locations

\begin{tabular}{|c|l|c|c|c|c|}
\hline Time & \multicolumn{1}{|c|}{ Location } & $\begin{array}{c}\text { Surface Profile } \\
(\mathrm{mg} / \mathrm{l})\end{array}$ & $\begin{array}{c}\text { Column Profile } \\
(\mathrm{mg} / \mathrm{l})\end{array}$ & $\begin{array}{c}\text { Bed Profile } \\
(\mathrm{mg} / \mathrm{l})\end{array}$ & $\begin{array}{c}\text { Model Prediction } \\
(\mathrm{mg} / \mathrm{l})\end{array}$ \\
\hline 8:00:00 AM & Inlet Sediment Trap & 30 & 26 & 150 & 29.3738 \\
\hline 9:00:00 AM & Inlet Sediment Trap & 27.7 & 26 & 150 & 25.52364 \\
\hline 10:00:00 AM & Outlet & 13.3 & 26 & 1100 & 11.4253 \\
\hline 11:00:00 AM & Inlet floodway & 13.5 & 26 & 1778 & 8.678 \\
\hline 12:00:00 PM & Floodway & 4.0 & 6 & 260 & 5.6594 \\
\hline 1:00:00 PM & Inlet of Agathis Lake & 2.7 & 35 & 526 & 8.7928 \\
\hline 2:00:00 PM & Inlet of Agathis Lake & 2.6 & 12 & 74 & 8.3827 \\
\hline 3:00:00 PM & Water body of lake & 0.9 & 6 & 12 & 0.9265 \\
\hline 4:00:00 PM & Water body of lake & 1.1 & 6 & 16 & 0.914 \\
\hline 5:00:00 PM & Water body of lake & 2.0 & 6 & 8 & 1.9757 \\
\hline 6:00:00 PM & Water body of lake & 3.0 & 4 & 6 & 2.5871 \\
\hline 7:00:00 PM & Water body of lake & 3.0 & 8 & 18 & 2.6023 \\
\hline 8:00:00 PM & Outlet of Agathis Lake & 1.3 & 18 & 20 & 1.0193 \\
\hline 9:00:00 PM & Outlet of Agathis Lake & 1.3 & 10 & 10 & 1.0193 \\
\hline 7:00:00 AM & Outlet of Agathis Lake & 2.5 & 38 & 60 & 2.193 \\
\hline 8:00:00 AM & Outlet of Agathis Lake & 2.5 & 20 & 54 & 2.1942 \\
\hline
\end{tabular}


Table 2. Type of modelled TSS in Agathis Lake

\begin{tabular}{|c|l|c|c|c|c|}
\hline Time & \multicolumn{1}{|c|}{ Location } & $\begin{array}{c}\text { TSS Mixed } \\
(\mathrm{mg} / \mathrm{l})\end{array}$ & $\begin{array}{c}\text { Volatile Solid } \\
(\mathrm{mg} / \mathrm{l})\end{array}$ & $\begin{array}{c}\text { Fixed Solid } \\
(\mathrm{mg} / \mathrm{l})\end{array}$ & $\begin{array}{c}\text { Model Prediction } \\
(\mathrm{mg} / \mathrm{l})\end{array}$ \\
\hline 8:00:00 AM & Inlet Sediment Trap & 30 & 22 & 8 & 29.3738 \\
\hline 9:00:00 AM & Inlet Sediment Trap & 27.7 & 20 & 7.7 & 25.52364 \\
\hline 10:00:00 AM & Outlet & 13.3 & 7 & 6.3 & 11.4253 \\
\hline 11:00:00 AM & Inlet floodway & 13.5 & 6 & 7.5 & 8.678 \\
\hline 12:00:00 PM & Floodway & 4.0 & 2 & 2 & 5.6594 \\
\hline 1:00:00 PM & Inlet of Agathis Lake & 2.7 & 1 & 1.7 & 8.7928 \\
\hline 2:00:00 PM & Inlet of Agathis Lake & 2.6 & 1 & 1.6 & 8.3827 \\
\hline 3:00:00 PM & Water body of lake & 0.9 & 0 & 0.9 & 0.9265 \\
\hline 4:00:00 PM & Water body of lake & 1.1 & 0 & 1.1 & 0.914 \\
\hline 5:00:00 PM & Water body of lake & 2.0 & 1 & 1 & 1.9757 \\
\hline 6:00:00 PM & Water body of lake & 3.0 & 1 & 2 & 2.5871 \\
\hline 7:00:00 PM & Water body of lake & 3.0 & 1 & 2 & 2.6023 \\
\hline 8:00:00 PM & Outlet of Agathis Lake & 1.3 & 0.3 & 1 & 1.0193 \\
\hline 9:00:00 PM & Outlet of Agathis Lake & 1.3 & 0.3 & 1 & 1.0193 \\
\hline 7:00:00 AM & Outlet of Agathis Lake & 2.5 & 0.5 & 2 & 2.193 \\
\hline 8:00:00 AM & Outlet of Agathis Lake & 2.5 & 0.5 & 2 & 2.1942 \\
\hline
\end{tabular}

After RMA-GEN of Agathis Lake is well-constructed, the next stage is making ccline as inflow and outflow of Agathis Lake. The inflow in the system that is made on RMA-GEN is a sediment trap inlet and the outflow of RMA-GEN is the outlet of Agathis Lake. Figure 5 and 6 depict the location of inflow and outflow locations.

After RMA-GEN is completed, the next program is creating RMA-10. This program generates velocity distribution on the system. The data for modelling under wetland scenarios conditions is similar to the existing condition by entering the value of the variables that are generated through the calibration result [11].

Wetland on Agathis Lake is designed to have seven ponds where there is elevation differences in each pond. In addition, there is a barrier in the form of beronjong (gravel-type) stone with water permeable properties between the ponds. This condition must be considered because it has different hydraulic properties. The considerable data that is entered into the RMA-10 program is the value of the Manning coefficients of the elements that act as barriers between wetland pools. Figure 7 figures a sample of elements that serve as a barrier between the ponds in the form of stones.

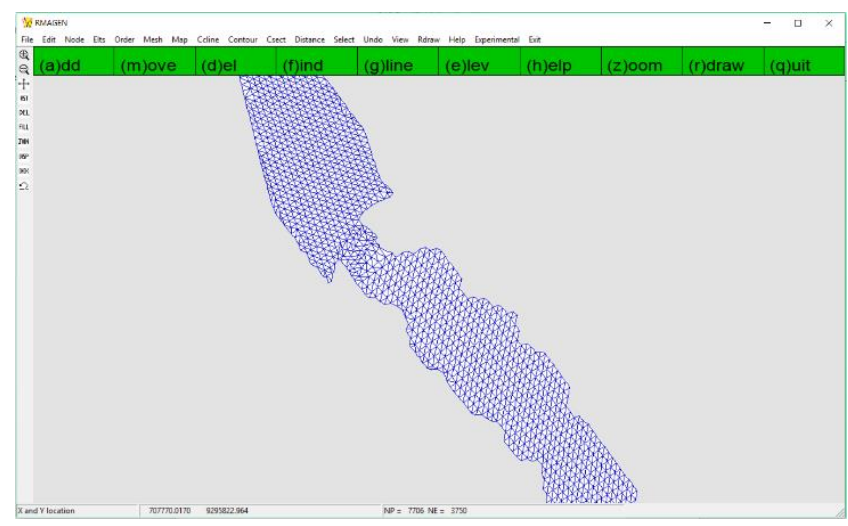

Fig. 7. Elements with variation of manning coefficient

The same steps are done for all the pools on the wetland of Agathis Lake. All of elements that have function as a delimiter and are filled with stone mason should have Manning numbers on the RMA-10 program.
After that, the RMA-10 program for Agathis Lake with the condition of having wetland is ready to run. Figure 8 and 9 depict the result of RMA-10 program.

Development of RMA-11 under these conditions continues the RMA-10 results of the same model. This program produced a constituent distribution that is modelled of this study, TSS, on the system. The data input in this model is the same as the RMA program model for Agathis Lake of the existing condition. Data in the form of variables that affect the results of RMA-11 is the result of calibration that has been done [11]. Figure 10-12 are samples of the results of the RMA-11 program running in the form of TSS constituents distribution at a certain time. The presence of wetland in Lake Agathis is expected to reduce the rate of polluted constituents that occur. The initial hypothesis of this scenario is that wetland is able to reduce the pollutant load that will enter the Lake Agathis. Here is a comparison of the results of running the TSS constituent RMA-11 program on existing conditions and conditions with wetland. Figure 13 shows the nodes or locations that would be compared with the existing physical condition of Agathis Lake. The running of the RMA-11 program for all nodes in the Agathis Lake model with wetland scenario is presented in Figure 14.

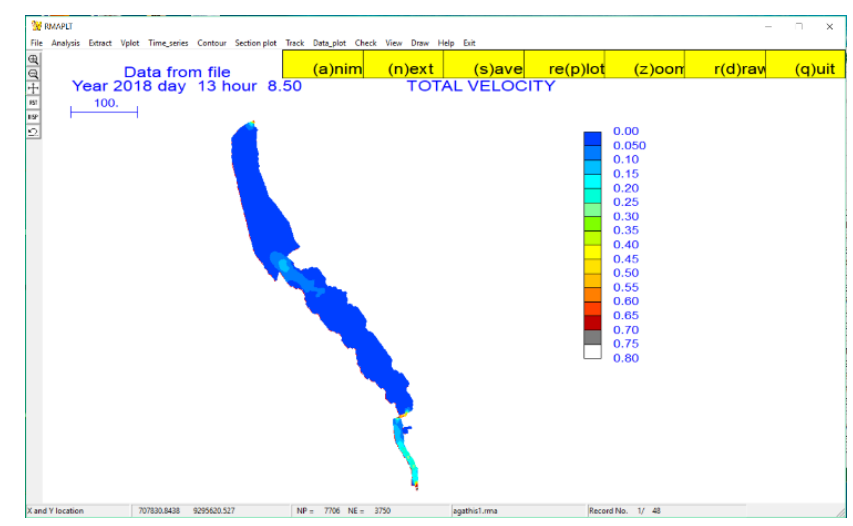

Fig. 8. Velocity distribution at $8.30 \mathrm{am}$ 


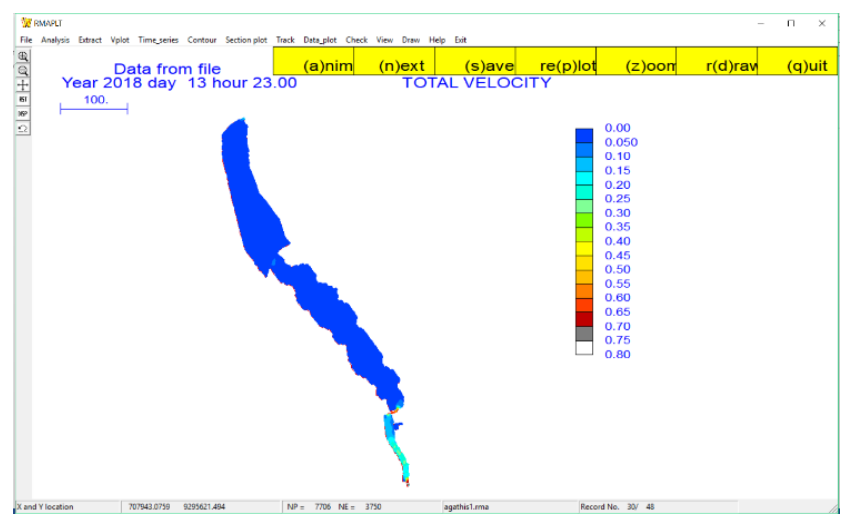

Fig. 9. Velocity distribution at $11.00 \mathrm{pm}$

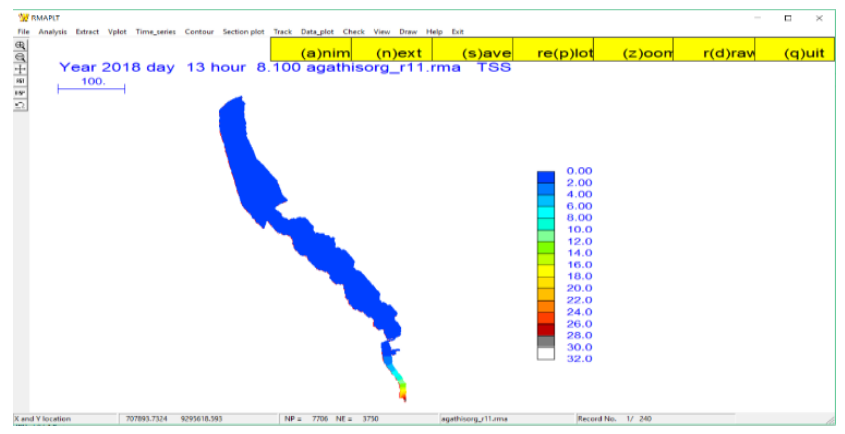

Fig. 10. TSS distribution at 8.06 am

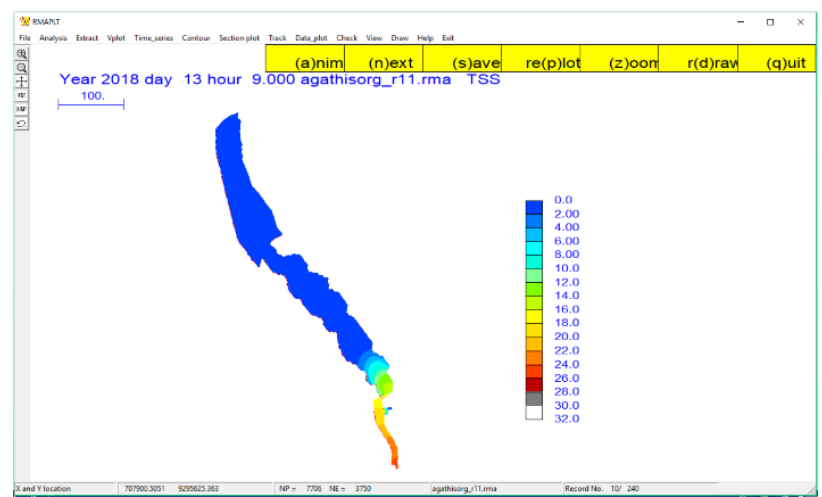

Fig. 11. TSS distribution at $9.00 \mathrm{am}$

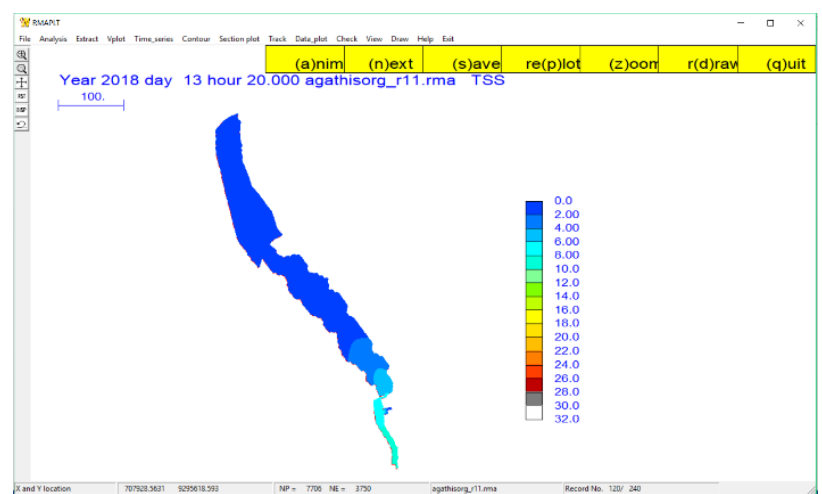

Fig. 12. TSS distribution at $8.00 \mathrm{pm}$

Based on the analysis of the program running results, with the presence of wetland, the lake can reduce the concentration of TSS that leads to water bodies by $35 \%$. This result is a comparison of node (node 3376) in the Agathis Lake inlet between the existing and the simulation with wetland scenario. Wetlands can significantly affect TSS levels in the Agathis Lake system. Figure 15 shows the response that occurs in the Agathis Lake inlet. The initial condition of the Agathis Lake system is all of nodes have initial concentration of 0 $\mathrm{mg} / \mathrm{l}$. Then, the pollutant loads enter the Agathis Lake system and are distributed within the system. In this section, time has a function as an independent function and concentration as a dependent function. One of the factors that play an important role in the assimilation process in the lake is the Eigen value, where this value is the sum of $\mathrm{Q} / \mathrm{V}+\mathrm{v} / \mathrm{H}$ (no chemistry reaction). When pollutant loads enter into a larger volume system, the concentration decreases and the travel time becomes longer. This condition could be happened because if the eigen value is small, then the response of the lake will decrease. Hence, the result of Figure 15 is reasonable.

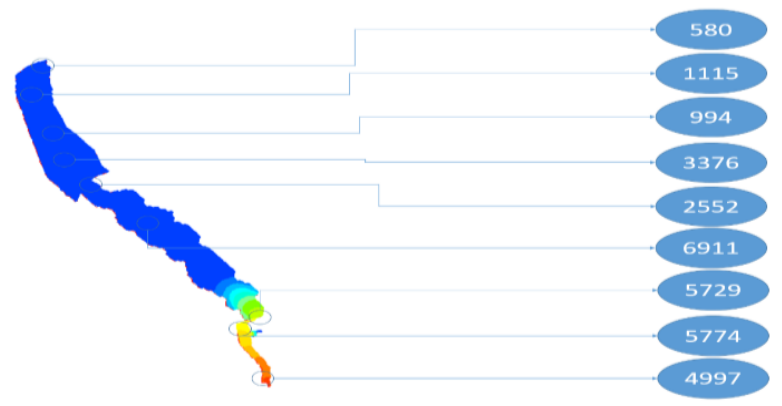

Fig. 13: Nodes location for model

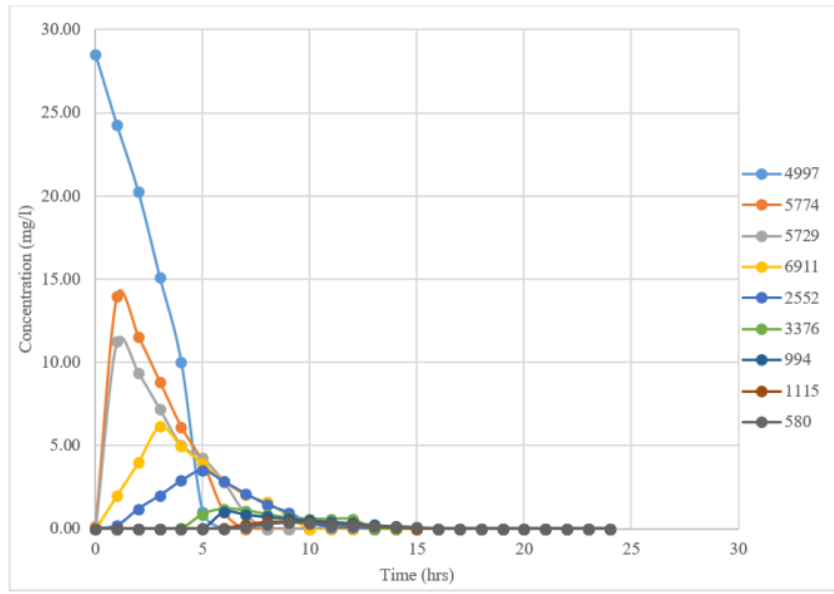

Fig. 14: Nodes responds due to TSS pollutant

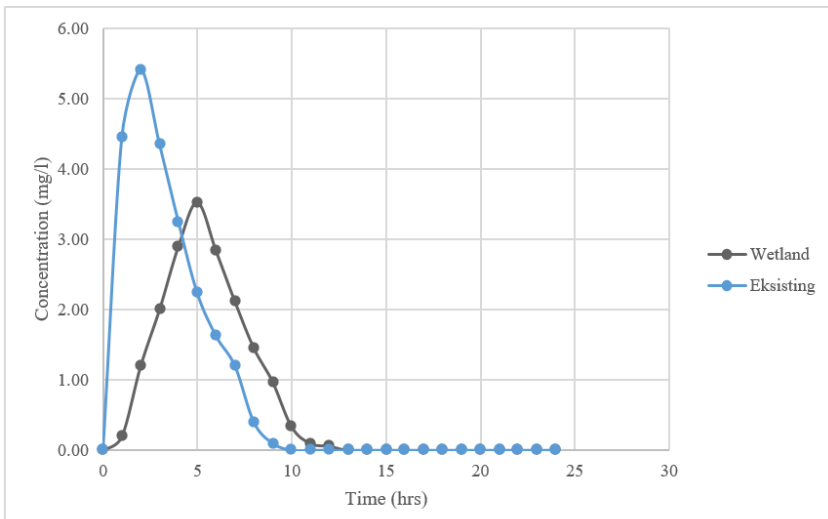

Fig. 15: Nodes responds due to TSS pollutant in inlet of system 


\subsection{Simulation II: High discharge condition}

The second scenario analysis is analysing the sediment trap response when the incoming discharge from the system inlet is based on the hydrograph of the flood condition. This physical analysis is performed according to the model under existing conditions.

The results of the RMA-11 program running are as follows. Based on the results of the running program, the required travel time for the TSS concentration from the system inlet to the outlet of the lake is 5 hours 18 minutes when the flood occurs. While under the normal average discharge condition, the required travel time is 11 hours 42 minutes.

Figure 16 and 17 show the comparative time required to achieve optimum TSS levels in the water body node (node 590). During flood discharge condition, the highest concentration of TSS to reach node 590 from the inlet takes 4 hours, while the average discharge condition takes 5.5 hours. This analysis can be concluded that flood discharge conditions affect the time required for a site in the lake system to achieve the highest TSS concentration. Flood discharge scenario in the model could reach maximum concentration in each node faster.

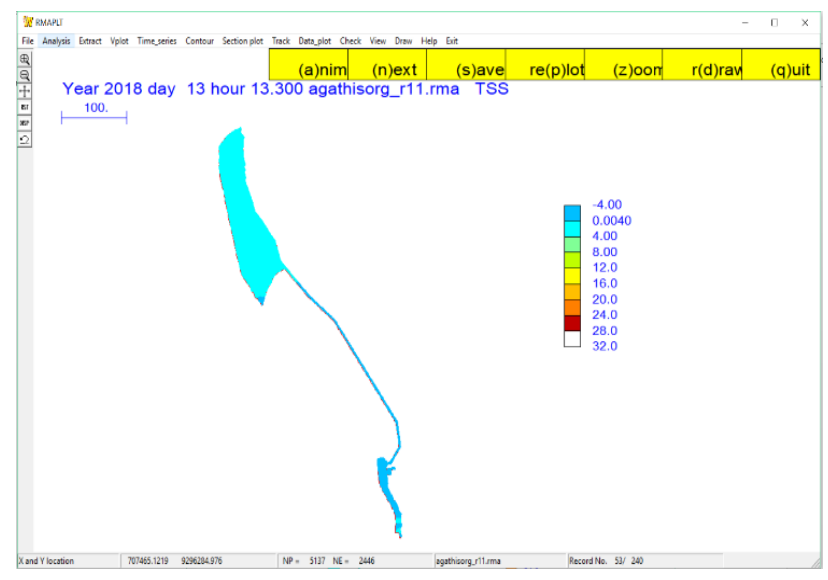

Fig. 16: Running program of RMA-11 during flood condition

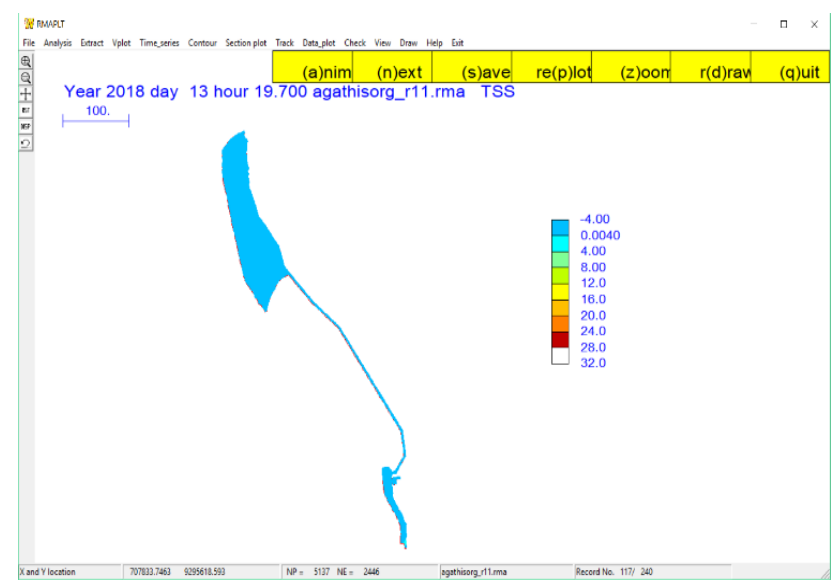

Fig. 17: Running program of RMA-11 in existing condition (normal)

Figure 18 depicts the response of phenomena that occurs on sediment traps and water bodies of Agathis Lake. According to Chapra [14] formulation, $\mathrm{C}=\mathrm{W} / \mathrm{Q}$ or concentration is obtained from loading per discharge into the system. The greater of the discharge that enters the system, the smaller of the concentration that occurs. When flood condition occurs, there is an increase of debit or flushing that could make the pollutant concentration dilutes or decreases.

In addition, because of the large Eigen values, the response to the pollutants will be faster. This is commonly known as the dilution phenomenon in which when large discharges occur in the system, the concentration will decrease as it moves faster to the outflow. Based on the results of the program running of RMA-11 program, the model shows the rational model results. Based on Figure 18 , the percentage of reduced TSS concentration due to flushing in the sediment trap is $19.47 \%$.

One of the functions of the existence of sediment trap on Agathis Lake is the physical process of sediment deposition that will enter the Agathis Lake. Supposedly, the concentration of TSS that occurs in the downstream will decrease. The occurrence of additional sediment concentrations in the downstream area may occur due to several factors. One of them is the scour from the surface.

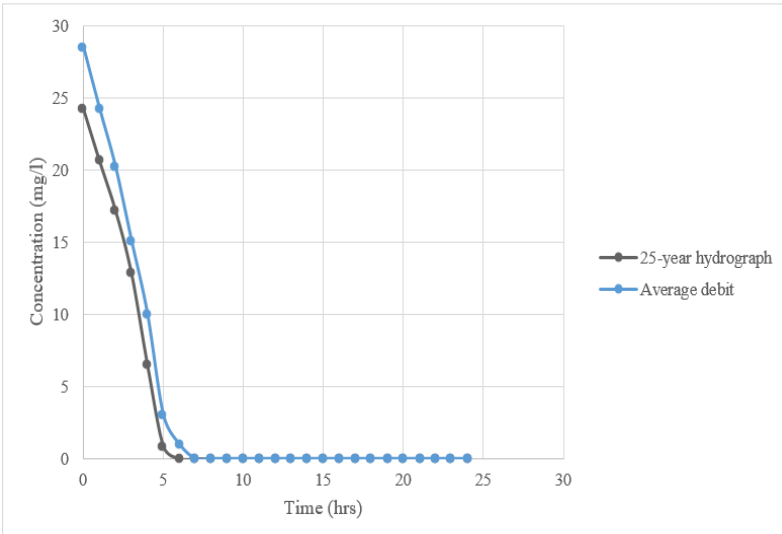

Fig. 18: Sediment trap respond due to TSS Pollutant during flood condition

\section{Conclusions}

Previous research suggests analysing various water column of the water body to take the samples due to irrelevant result between program output data and real condition. The novelty of this research is the finding of a representative sample for modeling the TSS pollutant on lakes. The representative sample in this model is located in the surface profile and the type of TSS is TSS (mixed). The first simulation provides information that the model behaviour for wetland scenario represents the theoretical aspect. So does the second simulation. It gives a reasonable correlation between pollutant loading, discharge, and concentration of TSS characteristics. Hence, both simulation I and II give reasonable result and can give various future conditions of Agathis Lake, so the policy recommendation could be analysed by employing this final program output data model. 
The authors wish to thank PITTA research grant No. 2511/UN2.R3.1/HKP.05.00/2018 from Universitas Indonesia as financial support to this research. The present work was performed as a part of main research entitled Developing Sediment Transport Modelling on Agathis Lake, Universitas Indonesia. Authors wish to thank Hydrology, Hydraulic, and River Laboratory of Engineering Faculty, Universitas Indonesia and Indonesian Institute of Science of Limnology (LIPI Limnology). The first author wishes to thank Indonesia Endowment Fund for Education scholarship (LPDP), which legislated by Indonesian Finance Ministry, as financial assistance to pursue a master program in Universitas Indonesia.

\section{References}

1. W. S. Merritt, R. A. Letcher, and A. J. Jakeman, $A$ review of erosion and sediment transport models, Environmental Modelling and Software 18, 761-799 (2003)

2. J. E. Parsons, D. L. Thomas, R. L. Huffman, (Eds.), Non-point source water quality models: Their use and application, Final Report of USDA-CSREES Southern Region Research Project S273, Development and Application of Comprehensive Agricultural Ecosystems Models, 200 pp (2001)

3. R. A. Young, C. A. Onstad, D. D. Bosch, W. P. Anderson, AGNPS, agricultural nonpoint source pollution. A watershed analysis tool, Conservation Research Report 35. US Department of Agriculture, Washington, DC (1987)

4. A. Jakeman, I. Littlewood, P. Whitehead, Computation of the instantaneous unit hydrograph and identifiable component flows with application to two small upland catchments, Journal of Hydrology 117, 275-300 (1990)

5. A. Jakeman, D. Post, M. Beck, From data and theory to environmental model: the case of rainfall runoff, Environmetrics 5, 297-314 (1994a)

6. A. Jakeman, D. Post, S. Schreider, Y. W. Yu, Modelling environmental systems: partitioning the water balance at different catchment scales, In: Zannetti, P. (Ed.), Computer Techniques in Environmental Studies V, Computational Mechanics Publications, Southampton, pp. 157-170 (1994b)

7. C. Dietrich, T. R. Green, A. J. Jakeman, An analytical model for stream sediment transport: application to Murray and Murrumbidgeereaches, Australia, Hydrological Processes 13 (5), 763-776 (1999)

8. M. Kusumah, , H. Soeryantono, D. R. Marthanty, The development of simulator for $2 D$ phosphorus concentration distribution in Mahoni Lake by using Resource Modelling Associates (RMA) Program, B. Eng. Thesis, Dept. Civil Engineering, Universitas Indonesia, Depok, 2016.

9. N. K. Izzaty, , H. Soeryantono, D. R. Marthanty, The simulation of phosphorus constituent distribution in Agathis and Ulin Lakes of Universitas Indonesia by using Resource Modelling Associates (RMA) Program, B. Eng. Thesis, Dept. Civil Engineering, Universitas Indonesia, Depok, 2017.
10. A. Hermawan, , H. Soeryantono, D. R. Marthanty, The simulation of nitrogen concentration distribution in Agathis and Ulin Lakes of Universitas Indonesia by using Resource Modelling Associates (RMA) Program, B. Eng. Thesis, Dept. Civil Engineering, Universitas Indonesia, Depok, 2017.

11. R. M. S. Prastica, H. Soeryantono, D. R. Marthanty, Constructing Total Suspended Solid Modelling on Agathis Lake by Employing Resource Modelling Associates Program, Proceedings of Padjadjaran Earth Dialogues: International Symposium on Geophysical Issues (2018)

12. R. M. S. Prastica, "Employing Galerkin method and field study for model calibration to perform sediment transport modelling in Agathis Lake" AIP Conference Proceedings 2014, 020-070 (2018)

13. R. M. S. Prastica, , H. Soeryantono, D. R. Marthanty, Developing hydrodynamic and sediment transport modelling on lakes: a preliminary study, International Journal of Environmental Science and Development, 9 No. 3, 49-55 (2018)

14. S. C. Chapra, Surface Water Quality Modelling, New York: McGraw-Hill International Editions (1997) 